\title{
Lipopolysaccharides Derived from Pantoea agglomerans Can Promote the Phagocytic Activity of Amyloid $\beta$ in Mouse Microglial Cells
}

\author{
YUTARO KOBAYASHI ${ }^{1}$, HIROYUKI INAGAWA $^{1,2,6}$, CHIE KOHCHI $^{1,3}$, KATSUICHIRO OKAZAKI $^{4}$, \\ RAN ZHANG ${ }^{2}$, HIDEKI KOBARA ${ }^{5}$, TSUTOMU MASAKI ${ }^{5}$ and GEN-ICHIRO SOMA ${ }^{1,2,6}$ \\ Departments of ${ }^{1}$ Integrated and Holistic Immunology, and ${ }^{5}$ Gastroenterology and Neurology, Faculty of Medicine, \\ and ${ }^{4}$ Department of Applied Biological Science, Faculty of Agriculture, Kagawa University, Kagawa, Japan; \\ ${ }^{2}$ Control of Innate Immunity, Technology Research Association, Kagawa, Japan; \\ ${ }^{3}$ Macrophi Inc., Takamatsu, Kagawa, Japan; \\ ${ }^{6}$ Research Institute for Healthy Living, Niigata University of Pharmacy and Applied Life Sciences, Niigata, Japan
}

\begin{abstract}
Background/Aim: Recent studies reported that lipopolysaccharide (LPS) exhibits beneficial effects on prevention of immune-related diseases by activating macrophages. We previously demonstrated that pre-treatment with LPS derived from Pantoea agglomerans (LPSp) activated amyloid $\beta(A \beta)$ phagocytosis in mouse primary microglia. In the present study, we further examined the promotory effect on phagocytosis of phagocytic particles in the C8-B4 microglia cell line. Materials and Methods: Phagocytic analysis of C8B4 cells was evaluated using phagocytic particles (latex beads or HiLyte ${ }^{T M}$ Fluor 488-conjugated $\left.A \beta_{1-42}\right)$. Results: The phagocytic activity of latex beads was dependent on the concentration of beads and incubation time. LPSp, at as low as $100 \mathrm{pg} / \mathrm{ml}$, significantly increased phagocytosis against the beads. In the experiment of $A \beta_{1-42}$ phagocytosis, LPSp significantly increased $A \beta$ phagocytic activity. Conclusion: LPSp treatment was confirmed to enhance $A \beta_{1-42}$ phagocytosis by mouse microglia. It is suggested that the use of LPSp may be a potential promising candidate for the prevention of Alzheimer's disease.
\end{abstract}

Lipopolysaccharide (LPS) is the major component of the outer membrane of Gram-negative bacterium. LPS has generally only been thought of as an endotoxin because it is a strong inducer of immune response in humans and animals.

Correspondence to: Dr. Yutaro Kobayashi, Faculty of Medicine, Kagawa University, 2217-16 FROM-KAGAWA Bio Lab., Hayashicho, Takamatsu-shi, Kagawa-ken, 761-0301, Japan. Tel/Fax: +81 878139203,e-mail: kobayashi@shizenmeneki.org

Key Words: Lipopolysaccharide, microglia, toll-like receptor, Pantoea agglomerans, amyloid $\beta$.
However, recent studies have demonstrated some beneficial effects on health. Braun-Fahrländer et al. reported that a higher exposure to environmental LPS in childhood was correlated with a lower incidence of asthma (1). Yoshida et al. demonstrated that pre-treatment with low-dose LPS via intravenous injection enhanced resistance to Staphylococcus aureus in a mouse model of infection with $S$. aureus and its possible mechanisms appear to be an activation (priming) of macrophages via epigenetic changes induced by LPSmediated toll-like receptor (TLR) 4 signaling pathways (2). In our previous study, oral administration of LPS derived from Pantoea agglomerans (LPSp), enhanced phagocytic activity by priming of peritoneal macrophages via TLR4 signaling pathways in mice (3). Our clinical studies demonstrated that oral treatment with LPSp would be effective for therapy of malignant tumors (4) and prevention of osteoporosis (5).

Alzheimer's disease is an age-dependent neurodegenerative pathology characterized by a progressive and irreversible deterioration of cognitive functions. Although the etiology of Alzheimer's disease remains unknown, a consensus has emerged regarding the amyloid hypothesis. This widely accepted hypothesis posits that an imbalance between production and clearance of amyloid $\beta$ $(\mathrm{A} \beta)$, a main component peptide of the amyloid plaques found in brain of patients with Alzheimer's disease, is involved in neuronal network dysfunctions (6). Microglia, the brain-resident type of macrophage, plays a crucial role in the immune defense of the neural parenchyma (7). Microglial cells lacking TLR2, TLR4, or the co-receptor cluster of differentiation (CD) do not exhibit an enhanced phagocytic response to $A \beta$ (8). Furthermore, treatment with LPS (via intracranial route) (9) or monophosphoryl lipid A derived from Salmonella minnesota R595 LPS (MPL; via 
A

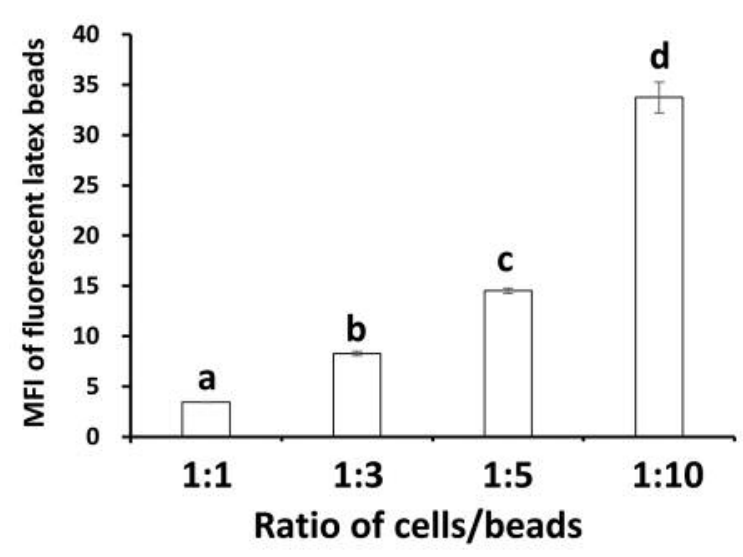

B



Figure 1. Analysis of C8-B4 cell phagocytosis of fluorescent latex beads. C8-B4 cells $\left(2 \times 10^{5}\right.$ cells/well) were incubated with different ratios of cells to fluorescent latex beads for different times at $37^{\circ} \mathrm{C}$. Before adding the beads, cells were pre-treated for 30 min with $50 \mu M$ cytochalasin D (CyD), an inhibitor of phagocytosis. The geometric mean fluorescence intensity (MFI) of beads was measured and the fluorescence of internalized beads was evaluated as: (MFI of sample without CyD treatment) - (MFI of the sample with CyD treatment). Data are presented as the mean $\pm S E M$ of four samples (one-way ANOVA with Tukey-Kramer's test). Values without a common letter are significantly different at $p<0.05$.

intraperitoneal route) (10) was found to reduce the cerebral $\mathrm{A} \beta$ accumulation in a mouse model of Alzheimer's disease. Our previous study demonstrated that LPSp pre-treatment enhanced $A \beta_{1-42}$ phagocytotic activity by primary mouse microglia (11). The aim of this study was to further examine the promotory effect on phagocytosis of phagocytic particles in microglia cell line C8-B4.

\section{Materials and Methods}

Cell culture and treatment. Mouse microglial cell line C8-B4 (CRL2540, American Type Culture Collection, Manassas, VA, USA) was grown in Dulbecco's modified Eagle's medium (Thermo Fisher Scientific, Waltham, MA, USA) supplemented with 100 units/ml penicillin-streptomycin and $10 \%$ fetal bovine serum (FBS) (Thermo Fisher Scientific). The C8-B4 cells $\left(2.0 \times 10^{5}\right.$ cells/well $)$ were seeded in a 48 -well tissue culture plate then incubated with LPSp (Macrophi, Kagawa, Japan) for $18 \mathrm{~h}$ at $37^{\circ} \mathrm{C}$. Negative control cells were treated with medium only. After the incubation, the cells were washed twice with Dulbecco's modified Eagle's medium and incubated with phagocytic particles for $3 \mathrm{~h}$ at $37^{\circ} \mathrm{C}$. In the present study, we used fluorescent latex beads (Fluoresbrite ${ }^{\circledR}$ YG Microspheres $2.0 \mu \mathrm{m}$; Polysciences, Warrington, PA, USA) at cell/bead ratios between 1:1 and 1:10 or HiLyte $^{\text {TM }}$ Fluor- 488 labeled $\mathrm{A} \beta_{1-42}$ peptide (HF488-A $\beta_{1-42}$; Anaspec, Fremont, CA, USA) at $10 \mathrm{ng} /$ well. The latex beads, formed from polystyrene microspheres, were used to evaluate a non-selective phagocytosis. Cytochalasin D (CyD; Wako, Osaka, Japan), an inhibitor of phagocytosis, was used at $50 \mu \mathrm{M}$ and cells were pre-treated or not for $30 \mathrm{~min}$ before adding the phagocytic particles. To remove non-internalized particles, cells were washed twice with ice-cold Phosphate-buffered saline. Cells were detached by $0.25 \%$ trypsin treatment and collected by centrifugation for $5 \mathrm{~min}$ at $300 \times \mathrm{g}$. Cell pellets were resuspended in hosphate-buffered saline containing $0.5 \%$ bovine serum albumin and $2 \mathrm{mM}$ EDTA. The geometric mean fluorescence intensity (MFI) of phagocytosed beads in the cells was measured using a Beckman Coulter Gallios flow cytometer using Kaluza software (Beckman Coulter, Indianapolis, IN, USA). The internalized fluorescence of phagocytosed beads was evaluated as follows: (MFI of sample without CyD treatment) (MFI of sample with CyD treatment), and the relative phagocytic activity was calculated by dividing the internalized fluorescence of phagocytosed beads of samples by that of the sample without LPSp treatment, as described previously (11).

Statistical analysis. Data are expressed as the mean \pm SEM. Statistical analyses were performed using StatMate V (ATMS, Tokyo, Japan). Statistical differences between multiple groups were determined using one-way ANOVA followed by Tukey-Kramer's test. A $p$-value of less than 0.05 was considered statistically significant.

\section{Results}

Phagocytic activity of C8-B4 cells toward fluorescent latex beads. The C8-B4 cells were incubated at cell/bead ratios of $1: 1,1: 3,1: 5$ or $1: 10$. As shown in Figure $1 \mathrm{~A}$, the phagocytic activity towards fluorescent latex beads was increased in a cell/bead ratio-dependent manner. In addition, the phagocytic activity increased in an incubation time-dependent manner at a cell/bead ratio of 1:5 (Figure 1B). The cell/bead ratio of 1:5 and $3 \mathrm{~h}$ incubation for the phagocytosis was selected for subsequent experiments. 


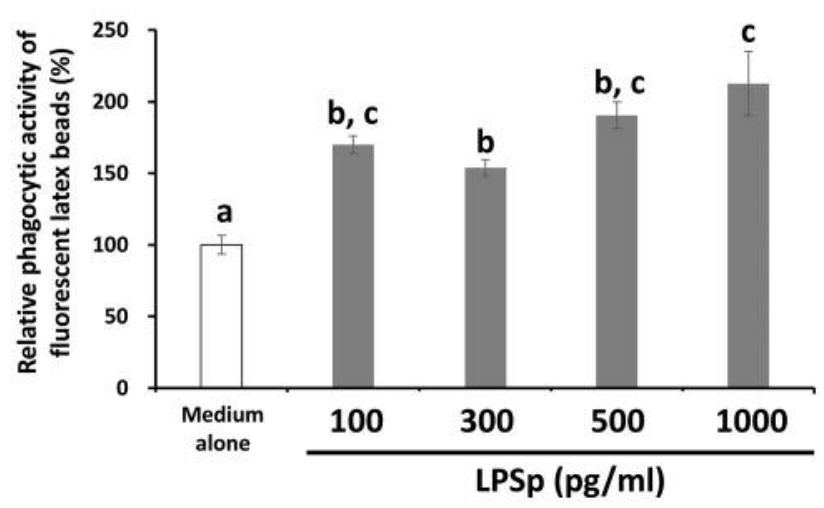

Figure 2. Analysis of phagocysis of fluorescent latex beads by C8-B4 cells treated with lipopolysaccharides derived from Pantoea agglomerans (LPSp). C8-B4 cells $\left(2 \times 10^{5}\right.$ cells/well) were pretreated with LPSp for $18 \mathrm{~h}$ and then incubated with fluorescent latex beads at cell/bead ratio of $1: 5$ at $37^{\circ} \mathrm{C}$ for $3 \mathrm{~h}$. Before adding the beads, cells were pretreated for 30 min with $50 \mu \mathrm{M}$ cytochalasin $D$, an inhibitor of phagocytosis. The geometric mean fluorescence intensity of beads was measured and the relative phagocytic activity was calculated by dividing the fluorescence of internalized beads of the sample by that of the negative control sample. Data are presented as the mean \pm SEM of four samples (one-way ANOVA with Tukey-Kramer's test). Values without a common letter are significantly different at $p<0.05$.

Effect of LPSp on the phagocytic activity against fluorescent latex beads. We next examined whether LPSp affected phagocytic activity against fluorescent latex beads. The phagocytic assay was performed using C8-B4 cells preincubated with LPSp for $18 \mathrm{~h}$. As shown in Figure 2, treatment with LPSp, at as low as $100 \mathrm{pg} / \mathrm{ml}$, significantly enhanced the relative phagocytosis of the fluorescent latex beads.

Effect of LPSp on the phagocytic activity against A $\beta$. We further examined whether LPSp promoted HF488-A $\beta_{1-42}$ phagocytic activity in the C8-B4 microglial cells. The cells were incubated with HF488-A $\beta_{1-42}$ at $10 \mathrm{ng} /$ well for $3 \mathrm{~h}$. As shown in Figure 3, LPSp treatment $(1 \mathrm{ng} / \mathrm{ml})$ significantly enhanced the relative phagocytosis of HF488-A $\beta_{1-42}$.

\section{Discussion}

In the present study, we demonstrated that pre-treatment with LPSp enhanced the phagocytic activity of fluorescent latex beads or HF488-A $\beta_{1-42}$ by the mouse microglial cell line C8B4 cells. Our previous study also indicated that the HF488$\mathrm{A} \beta_{1-42}$ phagocytosis by the mouse primary microglia was enhanced by LPSp treatment (11). These results are consistent with recent studies reporting that Juzen-taiho-to (JTT), a Chinese herbal medicine, and LPS, a major macrophageactivating substances found in JTT, increased the microglial phagocytosis of $\mathrm{A} \beta_{1-42}$ in primary microglia (12), and

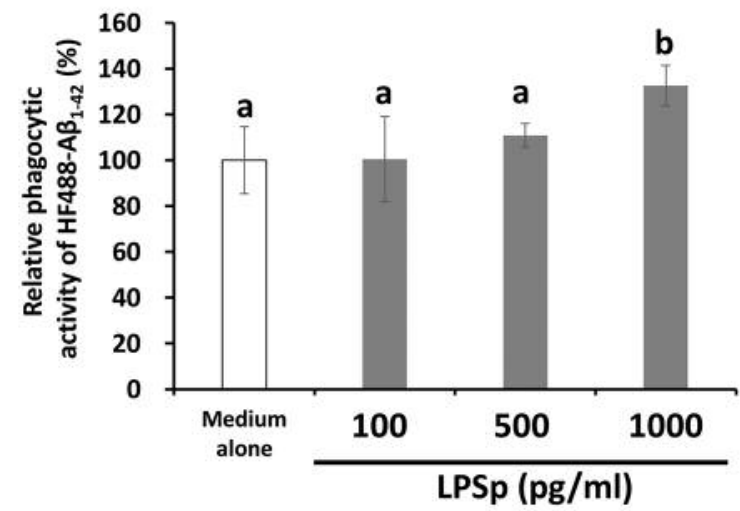

Figure 3. Analysis of phagocytosis of Fluor 488-conjugated amyloid $\beta$ (HF488-A $\beta_{1-42}$ ) particles by C8-B4 cells treated with lipopolysaccharides derived from Pantoea agglomerans (LPSp). C8-B4 cells $\left(2 \times 10^{5}\right.$ cells/well) were pretreated with LPSp for $18 \mathrm{~h}$ and incubated with HF488-A $\beta_{1-42}$ (10 ng/well) at $37^{\circ} \mathrm{C}$ for $3 \mathrm{~h}$. Before adding the beads, cells were pre-treated for 30 min with $50 \mu M$ cytochalasin $D$, an inhibitor of phagocytosis, before adding HF488-A $\beta_{1-42}$. The geometric mean fluorescence intensity of HF488-A $\beta_{1-42}$ was measured and the relative phagocytic activity was calculated by dividing the fluorescence of internalized HF488-A $\beta_{1-42}$ of the sample by that of the negative control sample. Data are presented as the mean \pm SEM of four samples (one-way ANOVA with Tukey-Kramer's test). Values without a common letter are significantly different at $p<0.05$.

monophosphoryl lipid $A$, and LPS, increased $A \beta_{1-42}$ phagocytosis by mouse microglia cell line BV-2 (10). However, further studies were required for elucidating the molecular mechanisms underlying the promotory effect of $\mathrm{A} \beta$ phagocytosis by LPSp. We previously demonstrated that the sublingual administration of LPSp increased antibody responses to influenza vaccine-specific IgG (in serum) and IgA (in nasal mucosa) (13). Oral treatment with LPSp inhibited the development of atopic dermatitis in NC/Nga mice (14). In addition, oral administration of LPS derived from the subaleurone layer of rice (15) or acetic acid bacteria (16) prevented pollen allergy via activating macrophage activity in a mouse model of cedar pollen allergy. These findings suggest that the effects of oral or sublingual administration of LPS involved regulation of the systemic immune system. Some clinical trials indicated that enhancement of $A \beta$ clearance by medical treatment led to a therapeutic effect on the brain level of $A \beta(17,18)$, implying that homeostatic regulation of immune responses in microglia by LPSp administration might be a potential preventive strategy for Alzheimer's disease.

\section{Acknowledgements}

This work was supported by the Council for Science, Technology and Innovation (CSTI), Cross-ministerial Strategic Innovation Promotion Program (SIP), "Technologies for creating nextgeneration agriculture, forestry and fisheries" (funding agency: Biooriented Technology Research Advancement Institution, NARO). 


\section{Conflicts of Interest}

The Authors have no financial conflicts of interest to declare interest in regard to this study.

\section{References}

1 Braun-Fahrländer C, Riedler J, Herz U, Eder W, Waser M, Grize L, Maisch S, Carr D, Gerlach F, Bufe A, Lauener RP, Schierl R, Renz H, Nowak D and Mutius E: Environmental exposure to endotoxin and its relation to asthma in school-age children. $\mathrm{N}$ Engl J Med 347: 869-877, 2002.

2 Yoshida K, Maekawa T, Zhu Y, Renard-Guillet C, Chatton B, Inoue $\mathrm{K}$, Uchiyama $\mathrm{T}$, Ishibashi $\mathrm{K}$, Yamada $\mathrm{T}$, Ohno $\mathrm{N}$, Shirahige K, Okada-Hatakeyama $M$ and Ishii $S$ : The transcription factor ATF7 mediates lipopolysaccharide-induced epigenetic changes in macrophages involved in innate immunological memory. Nat Immunol 16: 1034-1043, 2015.

3 Inagawa H, Kobayashi Y, Kohchi C, Zhang R, Shibasaki Y and Soma GI: Primed activation of macrophages by oral administration of lipopolysaccharide derived from Pantoea agglomerans. In Vivo 30: 205-212, 2016.

4 Morishima A and Inagawa $\mathrm{H}$ : Clinical effects of orally administered lipopolysaccharide derived from Pantoea agglomerans on malignant tumors. Anticancer Res 36: 3747-3751, 2016.

5 Nakata K, Nakata Y, Inagawa H, Nakamoto T, Yoshimura H and Soma G: Pantoea agglomerans lipopolysaccharide maintains bone density in premenopausal women: a randomized, doubleblind, placebo-controlled trial. Food Sci Nutr 2: 638-646, 2014.

6 Henry W. Querfurth HW and LaFerla FM: Alzheimer's disease. N Engl J Med 362: 329-344, 2010.

7 Streit WJ, Walter SA and Pennell NA: Reactive microgliosis. Prog Neurobiol 57: 563-581, 1999.

8 Reed-Geaghan EG, Savage JC, Hise AG and Landreth GE: CD14 and toll-like receptors 2 and 4 are required for fibrillar A $\beta$-stimulated microglial activation. J Neurosci 23: 1198211992, 2009.

9 Herber DL, Mercer M, Roth LM, Symmonds K, Maloney J, Wilson N, Freeman MJ, Morgan D and Gordon MN: Microglial activation is required for $A \beta$ clearance after intracranial injection of lipopolysaccharide in APP transgenic mice. J Neuroimmune Pharmacol 2: 222-231, 2007.

10 Michaud JP, Hallé M, Lampron A, Thériault P, Préfontaine P, Filali M, Tribout-Jover P, Lanteigne AM, Jodoin R, Cluff C, Brichard V, Palmantier R, Pilorget A, Larocque D and Rivest S: Toll-like receptor 4 stimulation with the detoxified ligand monophosphoryl lipid A improves Alzheimer's disease-related pathology. Proc Natl Acad Sci USA 110: 1941-1946, 2013.
11 Kobayashi Y, Inagawa H, Kohchi C, Okazaki K, Zhang R and Soma G: Effect of lipopolysaccharide derived from Pantoea agglomerans on the phagocytic activity of amyloid $\beta$ by primary murine microglial cells. Anticancer Res 36: 3693-3698, 2016.

12 Liu H, Wang J, Sekiyama A and Tabira T: Juzen-taiho-to, an herbal medicine, activates and enhances phagocytosis in microglia/macrophages. Tohoku J Exp Med 215: 43-54, 2008.

13 Fukasaka M, Asari D, Kiyotoh E, Okazaki A, Gomi Y, Tanimoto T, Takeuchi O, Akira S and Hori M: A lipopolysaccharide from Pantoea agglomerans is a promising adjuvant for sublingual vaccines to induce systemic and mucosal immune responses in mice via TLR4 pathway. Plos one 10: e0126849, 2015.

14 Wakame $\mathrm{K}$, Komatsu $\mathrm{K}$, Inagawa $\mathrm{H}$ and Nishizawa $\mathrm{T}$ : Immunopotentiator from Pantoea agglomerans prevents atopic dermatitis induced by Dermatophagoides farinae extract in NC/Nga mouse. Anticancer Res 35: 4501-4508, 2015.

15 Tamura Y, Inagawa H, Nakata Y, Kohchi C and Soma G: Effects of the subaleurone layer of rice on macrophage activation and protection of pollen allergy in a murine model. Anticancer Res 35: 4467-4472, 2015.

16 Amano S, Inagawa H, Nakata Y, Ohmori M, Kohchi $\mathrm{C}$ and Soma G: Oral administration of lipopolysaccharide of acetic acid bacteria protects pollen allergy in a murine model. Anticancer Res 35: 4509-4514, 2015.

17 Ostrowitzki S, Deptula D, Thurfjell L, Barkhof F, Bohrmann B, Brooks DJ, Klunk WE, Ashford E, Yoo K, Xu ZX, Loetscher H and Santarelli L: Mechanism of amyloid removal in patients with Alzheimer disease treated with gantenerumab. Arch Neurol 69: 198-207, 2012.

18 Masoumi A, Goldenson B, Ghirmai S, Avagyan H, Zaghi J, Abel K, Zheng X, Espinosa-Jeffrey A, Mahanian M, Liu PT, Hewison M, Mizwickie M, Cashman $J$ and Fiala $M: 1 \alpha$, 25dihydroxyvitamin $\mathrm{D}_{3}$ interacts with curcuminoids to stimulate amyloid-beta clearance by macrophages of Alzheimer's disease patients. J Alzheimers Dis 17: 703-717, 2009.
Received May 2, 2017

Revised May 22, 2017

Accepted May 23, 2017 